\title{
Exploration on the matching between Optical Comprehensive Design Experiment and Washington Accord
}

Yiping Cao, Wenjing Chen, Qican Zhang, Yuankun Liu, Dahai Li, et al.

Yiping Cao, Wenjing Chen, Qican Zhang, Yuankun Liu, Dahai Li, Xinzhi Zhou, Jun Wei, "Exploration on the matching between Optical Comprehensive Design Experiment and Washington Accord," Proc. SPIE 10452, 14th Conference on Education and Training in Optics and Photonics: ETOP 2017, 104526P (16 August 2017); doi: 10.1117/12.2269997

SPIE Event: 14th Conference on Education and Training in Optics and Photonics, ETOP 2017, 2017, Hangzhou, China 


\title{
Exploration on the Matching between Optical Comprehensive Design
}

\author{
Experiment and Washington Accord
}

\author{
Yiping Cao ${ }^{1}$, Wenjing Chen, ${ }^{1}$ Qican Zhang, ${ }^{1}$ Yuankun Liu, ${ }^{1}$ Dahai Li, ${ }^{1}$ Xinzhi Zhou, ${ }^{1}$ Jun Wei, ${ }^{1}$ \\ ${ }^{1}$ Opto-Electronics Department, Sichuan University, Chengdu, 610064, China
}

\begin{abstract}
Common problems faced in optical comprehensive design experiment and going against the Washington Accord are pointed out. For resolving these problems, an instructional and innovative teaching scheme for Optics Comprehensive Design Experiment is proposed. We would like to understand the student that can improve the hands-on practical ability, theory knowledge understanding ability, complex problem solving ability, engineering application ability, cooperative ability after tracking and researching the student who have attended the class about Optical Comprehensive Design Experiment, We found that there are some problems on the course such as the experiment content vague, the student beginning less time, phase separation theory and engineering application, the experiment content lack of selectivity and so on. So we have made some improvements reference to the Washington Accord for the class teaching plan about Optical Comprehensive Design Experiment. This class must relevant to the engineering basic courses, professional foundation course and the major courses, so far as to the future study and work that which can play a role in inheriting and continuity to the students. The Optical Comprehensive Design Experiment teaching program requires students learning this course to have learnt basic courses like analog electronics technique, digital electronic technique, applied optics and computer and other related courses which students are required to comprehensively utilize. This teaching scheme contains six practical complex engineering problems which are respectively optical system design, light energy meter design, illuminometer design, material refractive index measuring system design, light intensity measuring system design and open design. Establishing the optional experiment and open experiment can provide students with a greater choice and enhance the students' creativity, vivid teaching experimental teachers and enriching contents of experiment can make the experiment more interesting, providing students with more opportunities to conduct experiment and improving students' practical ability with long learning time, putting emphasis on student's understanding of complex engineering problems and the cognitive of the process to solve complex engineering problems with actual engineering problems. Applying the scheme in other courses and improving accordingly will be able to ensure the quality of engineering education. Look forward to offering useful reference for the curriculum system construction in colleges and universities.
\end{abstract}

Key Words: Washington Accord; complex problem; teaching scheme; Optics Design Experiment;

\section{Introduction}

The June 19, 2013 International Engineering Congress after a formal vote, unanimously agreed to accept China as a "Washington Accord " ready members [1], signifying China's engineering education certification has entered a substantive stage of implementation, which will have a great impact on the reform of higher education in China [2]. The essence of the Washington Accord is that the contracting Member States recognize that the certified professional meets the academic requirements of engineering practice and is of substantial equivalence. Substantial equivalence means: (1) The contracted engineering education that has been certified by Member States is equivalent between Member States; (2) The professional engineer in the contracting country is equivalent between the members. With the globalization of the world economy, the demand for engineering talents is also increasing, which requires the training of engineers in the higher engineering education system and the quality to be recognized by each other, and thus the student-oriented teaching program to strengthen engineering and practical education can ensure that engineering education in line with the needs of industrial development [3]. In the continuous 
development of optoelectronic technology today, the competition in the optoelectronic industry is essentially the competition of optoelectronic technology. Optical integrated design experiment combines a variety of integrated technologies such as analog electronic technology, digital electronic technology, wave optics, applied optics, computer technology, etc. It is an important way to cultivate students' photoelectric technology field and is an important way for practical ability and innovation ability of prism design, electronic circuit design, printed circuit board (PCB) production, photoelectric measurement technology and so on. It is a course which is formed by many disciplines. Therefore, with reference to Washington Accord, we have made some improvements to the teaching program of the optical integrated design experiment course, which must be related to the engineering basic course, the professional basic course and the professional course [4], and even to be associated with the future study and work of the students, so as to play the role of future. In view of the problems in the teaching concept of traditional optical integrated design experiment [5] (the teacher demonstrates it again and the student does it) and the lack of selective content (experimental content is single), we have made a full range of progress for the course, mainly for the course of curriculum skills training, teaching purposes and requirements, teaching content and so on. In order to make the course meets the certification criteria for solving complex problems in engineering education certification.

\section{Curriculum training ability}

Complex problems have the following characteristics: (1) With the need to use in-depth engineering principles, after analysis can be resolved; (2) Involving a wide range of technical, engineering and other factors, and may have a certain conflict with each other; (3) Need to establish a suitable abstract model to solve, in the modeling process need to reflect the creativity; (4) Not just by the usual method can be completely resolved; (5) The factors involved in the problem may not be fully contained in the standards and norms of professional engineering practice; (6) The problems has a high comprehensiveness, including multiple interrelated sub problems. The above characteristics show that for the integrated design of this course, we have to cultivate the students with the following abilities:

1. Ability to understand the forefront of the professional development of the status quo and trends, with the use of basic knowledge and the basic theoretical knowledge to solve practical engineering problems, with the system of engineering practice learning experience;

2. Ability to design and implement engineering experiments and the ability to analyze experimental results;

3. Ability to innovate, analyze and solve problems and to complete internship reports, research reports, or paper calculations, analysis, collation and writing independently;

4. Ability to design, implement and evaluate optical systems independently, and to select, use and develop appropriate tools for specific complex engineering problems;

5. Ability to comprehensively use knowledge and the modern optical methods to complete optical design, to draw reasonable and effective conclusions of the research report and ability to solve a specific complex engineering task;

6. Ability to manage knowledge, presentation and interpersonal skills and the ability to function in a team;

7. Ability to accomplish tasks in a team timely, to share information, to listen and to express one's point of view;

8. Ability to lead the team to complete team work and organizational management ability; 
9. Ability to learn autonomously, the awareness of lifelong learning and the ability to adapt to development;

10. Ability to be serious working style, scientific attitude and to take good care of state property, to abide by the virtues of discipline in order to be with humanities and social science literacy, social responsibility and engineering professional ethics.

\section{Teaching aims and requirements}

Teaching aims: The purpose of the experiment is to guide the students to flexibly apply deep theoretical knowledge and analytical means, in the process of system design, strengthening the consciousness of optical electromechanical integration, putting the idea of optical electromechanical integration into practice, and experiencing the organic combination of photo-electricity in practice. Train students' creative ability and ability to analyze and solve problems, so that students have the ability to complete the design, implementation and evaluation of the optical system independently.

Teaching requirements: 1 . Master the knowledge of engineering optics, wave optics, analog electronic technology, digital electronic technology, single chip microcomputer, and other related basic courses, specialized courses and laboratory courses; 2. Flexible application of theoretical knowledge of optics and electricity, basic experimental knowledge, experimental methods and experimental skills; 3. Learning system design report writing methods, with strict logical thinking way, and learn to express, complete the research report carefully; 4. Set up serious style of work, realistic scientific attitude, and feel the atmosphere of academic discussion and teamwork, and

enhance team spirit; 5 . Choose a topic of interest from the six topics of the teaching content, learn to analyze problems, design solutions, demonstration programs, implementation plans, and ultimately achieve system functions, so as to solve practical and complex problems.

\section{Teaching content setting}

This course provides six practical engineering problems:

A, Optical System Design (48 class hours): (1) to design a 6 times the Kepler telescope eyepiece with focal length of $F^{\prime}=25 \mathrm{~mm}$, diameter of exit pupil $\mathrm{D}^{\prime}=5 \mathrm{~mm}$, distance of exit pupil exit $>20 \mathrm{~mm}$, view angle $2 \mathrm{~W}^{\prime}=28$ degree considering the aberration compensation for objective lens, eyepiece taking off-axis aberration correction and objective lens taking off-axis aberration correction; (2) to design a 6 times the Kepler telescope objective lens with focal length, relative aperture, view angle and aberration compensation designed according to the requirements of (1) giving the concrete calculation process; (3) to combine the above eyepiece and objective lens into a Kepler telescope with the requirement that the angle aberration of the outgoing beam is less than 3 ' around. If it does not meet the requirement, it can be realized by paraxial ideal optical plane in ZEMAX, controlling the visual magnification or infinite combined focal length (for example, $f^{\prime}>100000$ ), etc. All designs employ visible light (F, d, C) band.

B, Light Energy Meter Design (48 class hours): to design a real-time measurement of light energy system utilizing the related knowledge of light and electricity comprehensively. The design requirements: (1) to adopt 51 single-chip microcomputer (SCM) as the main control chip; (2) to complete the detection circuit; (3) to solve the problem of power failure protection; (4) real-time display of light energy; (5) to complete the photoelectric signal conversion.

C, Illumination Meter Design (48 class hours): to design a real-time measurement of light illumination system utilizing the related knowledge of light and electricity comprehensively. The design requirements: (1) to adopt 51 SCM as the main control chip; (2) to complete the detection 
circuit; (3) to solve the problem of power failure protection; (4) real-time display of light illumination; (5) to complete the photoelectric signal conversion; (6) to have an intimate knowledge of the principle of illumination meter design.

D, Refractive Index Measurement (48 class hours): to design a set of practical material refraction index measurement methods based on the related basic courses, professional courses and experimental courses, such as wave optics, digital circuit and analog circuit. This course is a practice based technology experiment course it needs to design the optical system and hardware circuit, to complete the photoelectric conversion with the combination of physical signal and hardware circuit and finally to realize the accurate measurement of the material refractive index. The design requirements: (1) to adopt 51 SCM as the main control chip; (2) to complete the detection circuit; (3) to solve the problem of power failure protection; (4) to solve the problem of finding the first order interference fringes; (5) to complete the photoelectric signals conversion; (6) display circuit design.

E, Design of Light Intensity Collection System (48 class hours): to design a set of practical light intensity collection methods based on the related basic courses, professional courses and experimental courses, such as wave optics, digital circuit and analog circuit. This course is a practice based technology experiment course it needs to design the optical system and hardware circuit, to complete the photoelectric conversion with the combination of physical signal and hardware circuit and finally to realize the measurement of the light intensity. The design requirements: (1) to adopt 51 SCM as the main control chip; (2) to complete the detection circuit; (3) to solve the problem of power failure protection; (4) to complete the photoelectric signals conversion; (5) display circuit design.

F, Open Design (48 class hours): to design a set of innovative project to measure a selected physical quantity based on the related basic courses, professional courses and experimental courses, such as wave optics, digital circuit and analog circuit. This course is a practice based technology experiment course it needs to design the optical system and hardware circuit, to complete the photoelectric conversion with the combination of physical signal and hardware circuit and finally to realize the measurement of a selected physical quantity. The design requirements: (1) to adopt 51 SCM as the main control chip; (2) to complete the detection circuit; (3) to complete the photoelectric signals conversion; (4) display circuit design (5) to analyze the application value and significance (6) to show the innovation.

The problems in above six practical engineering projects have all the characteristics of complex problems in Washington Accord. These problems involve the knowledge of analog electronics, digital electronics, wave optics, applied optics, microcontroller, computer, etc, and can not be solved completely by the commonly used methods. Only to make a thorough analysis, to make rational use of the theoretical knowledge and to construct an abstract theoretical model can these practical problems be solved. The following is the introduction of the teaching process of the refractive index measurement experiment and the open design experiment in these six practical engineering projects. The contents of the other four experiments are followed by analogy. It should be noted that not to introduction does not mean that it is not important. The proposal of these six practical engineering projects is to provide students with the experimental choice of space so that students can perform in the direction they are interested in. Especially the creative experiment trains the students' creative ability comprehensively.

The experimental progress subdivision of Refractive Index Measurement and Open Design is as shown in Table 1 and Table 2, respectively. 
Table 1 Experimental progress subdivision of Refractive Index Measurement

\begin{tabular}{|c|c|c|c|}
\hline Num. & $\begin{array}{l}\text { Experimental } \\
\text { stage }\end{array}$ & Specific steps & $\begin{array}{l}\text { Characteristics } \\
\text { of } \\
\text { corresponding } \\
\text { complex } \\
\text { problems } \\
\end{array}$ \\
\hline \multirow{7}{*}{1} & \multirow{7}{*}{$\begin{array}{l}\text { Project design } \\
\text { (12 Class } \\
\text { hours) }\end{array}$} & Data collection and arrangement & \multirow{7}{*}{$\begin{array}{l}\text { (1), (2), (3), (4), } \\
\text { (5) and (6) }\end{array}$} \\
\hline & & Design requirement analysis & \\
\hline & & System overall project & \\
\hline & & $\begin{array}{l}\text { Simulation of the refractive index measurement } \\
\text { model using Matlab }\end{array}$ & \\
\hline & & $\begin{array}{l}\text { Circuit design principle of light path module, } \\
\text { photoelectric detection module, signal } \\
\text { conditioning module, AD conversion module, } \\
\text { display circuit module, power failure protection } \\
\text { module, power module, serial communication } \\
\text { module }\end{array}$ & \\
\hline & & Device selection of the above modules & \\
\hline & & Minimum system design of 51 SCM & \\
\hline \multirow[b]{2}{*}{2} & \multirow{2}{*}{$\begin{array}{c}\text { Project } \\
\text { demonstration } \\
\text { (4 Class hours) } \\
\end{array}$} & Verify the feasibility of the project & \multirow{2}{*}{$\begin{array}{l}(1),(2),(3),(4), \\
\quad(5) \text { and }(6)\end{array}$} \\
\hline & & Identification of the project final design & \\
\hline 3 & $\begin{array}{l}\text { Midterm reply } \\
\text { (4 Class hours) }\end{array}$ & Reply to the feasibility analysis of the design & $\begin{array}{l}\text { (1), (2), (3), (4), } \\
\text { (5) and (6) }\end{array}$ \\
\hline \multirow{14}{*}{4} & \multirow{14}{*}{$\begin{array}{l}\text { Specific Design } \\
\text { (20 Class } \\
\text { hours) }\end{array}$} & Design of the system light path & \multirow{14}{*}{ (3), (5) and (6) } \\
\hline & & Design of the photoelectric detection module & \\
\hline & & Design of the signal conditioning module & \\
\hline & & Design of the AD conversion module & \\
\hline & & Design of the display circuit module & \\
\hline & & Design of the power failure protection module & \\
\hline & & Design of the power module & \\
\hline & & Design of the serial communication module & \\
\hline & & Circuit simulation using Multism & \\
\hline & & Circuit schematic design using Protel99SE & \\
\hline & & Design of PCB using Protel99SE & \\
\hline & & Fabrication of PCB board & \\
\hline & & Welding and debugging of the circuit & \\
\hline & & Experimental data test & \\
\hline 5 & $\begin{array}{l}\text { Report Writing } \\
\text { (4 Class hours) }\end{array}$ & $\begin{array}{l}\text { The report contains the purpose of the experiment, } \\
\text { the content and requirements of the experiment, } \\
\text { the principle of measurement, the design of the } \\
\text { experimental project, the drawing of the PCB } \\
\text { schematic diagram, the references, the appendix } \\
\text { (the system circuit schematic diagram and the } \\
\text { PCB documents, etc.) }\end{array}$ & (1) \\
\hline 6 & $\begin{array}{c}\text { Final reply } \\
\text { (4 Class hours) }\end{array}$ & $\begin{array}{l}\text { Ask and answer questions related to the overall } \\
\text { design, detailed design, experimental results, team } \\
\text { management, costs, engineering and legal } \\
\text { knowledge, etc. }\end{array}$ & $\begin{array}{l}\text { (1), (2), (3), (4), } \\
\text { (5) and (6) }\end{array}$ \\
\hline
\end{tabular}


Table 2 Experimental progress subdivision of Open Experiment

\begin{tabular}{|c|c|c|c|}
\hline Num. & $\begin{array}{l}\text { Experimental } \\
\text { stage }\end{array}$ & Specific steps & $\begin{array}{c}\text { Characteristics } \\
\text { of } \\
\text { corresponding } \\
\text { complex } \\
\text { problems }\end{array}$ \\
\hline \multirow{8}{*}{1} & \multirow{8}{*}{$\begin{array}{l}\text { Project design } \\
\text { (12 Class } \\
\text { hours) }\end{array}$} & $\begin{array}{l}\text { Data collection and arrangement selecting a } \\
\text { innovative design topic }\end{array}$ & \multirow{8}{*}{$\begin{array}{l}\text { (1), (2), (3), (4), } \\
\text { (5) and (6) }\end{array}$} \\
\hline & & $\begin{array}{l}\text { Analysis of the selected topic's application value } \\
\text { and significance }\end{array}$ & \\
\hline & & Analysis of innovation & \\
\hline & & Analysis of design requirements & \\
\hline & & System overall project & \\
\hline & & Circuit design principle of modules & \\
\hline & & Device selection of modules & \\
\hline & & Minimum system design of 51 SCM & \\
\hline \multirow[b]{2}{*}{2} & \multirow{2}{*}{$\begin{array}{c}\text { Project } \\
\text { demonstration } \\
\text { (4 Class hours) }\end{array}$} & Verify the feasibility of the project & \multirow{2}{*}{$\begin{array}{l}\text { (1), (2), (3), (4), } \\
\text { (5) and (6) }\end{array}$} \\
\hline & & Identification of the project final design & \\
\hline 3 & $\begin{array}{l}\text { Midterm reply } \\
\text { (4 Class hours) }\end{array}$ & Reply to the feasibility analysis of the design & $\begin{array}{l}\text { (1), (2), (3), (4), } \\
\text { (5) and (6) }\end{array}$ \\
\hline \multirow{7}{*}{4} & \multirow{7}{*}{$\begin{array}{l}\text { Specific Design } \\
\text { (20 Class } \\
\text { hours) }\end{array}$} & Design of the system light path & \multirow{7}{*}{ (3), (5) and (6) } \\
\hline & & Circuit simulation using Multism & \\
\hline & & Circuit schematic design using Protel99SE & \\
\hline & & Design of PCB using Protel99SE & \\
\hline & & Fabrication of PCB board & \\
\hline & & Welding and debugging of the circuit & \\
\hline & & Experimental data test & \\
\hline 5 & $\begin{array}{l}\text { Report Writing } \\
\text { (4 Class hours) }\end{array}$ & $\begin{array}{l}\text { The report contains the purpose of the experiment, } \\
\text { the content and requirements of the experiment, } \\
\text { the principle of measurement, the design of the } \\
\text { experimental project, the drawing of the PCB } \\
\text { schematic diagram, the references, the appendix } \\
\text { (the system circuit schematic diagram and the } \\
\text { PCB documents, etc.) }\end{array}$ & (1) \\
\hline 6 & $\begin{array}{c}\text { Final reply } \\
\text { (4 Class hours) }\end{array}$ & $\begin{array}{l}\text { Ask and answer questions related to the overall } \\
\text { design, detailed design, experimental results, team } \\
\text { management, costs, engineering and legal } \\
\text { knowledge, etc. }\end{array}$ & $\begin{array}{l}\text { (1), (2), (3), (4), } \\
\text { (5) and (6) }\end{array}$ \\
\hline
\end{tabular}

As Table 1 shows the experimental stage are corresponding to characteristics of complex engineering problems and the project design, project demonstration and interim reply is closely related to characteristics of the six complex engineering projects. And the three steps repeat demonstrations to the major characteristics to find a comprehensive solution to the complex problem actual project. In the specific design stage the experiment is from theory to practice involving all aspects of the problems. The students need to design, manufacture, and weld and debug in order to obtain the correct and accurate experimental results. The Experimental progress subdivision of open design experiment is shown in Table 2. Its difference with the refractive index measurement is that there is no identified engineering problem in the experiment so that students need to find engineering 
problems with innovative and practical application value according to the life experience. The innovation of this experiment must be related to optical information science and engineering since this course is the core course of optical information science and engineering major. As a result, students will have a comprehensive grasp of the whole process of solving the complex problems of light, mechanical and electrical engineering and lay a solid foundation for future study and work.

\section{Reference}

[1] Xinhua Abroad, The quality of engineering education has been internationally recognized China's accession to the Washington accord [EB/OL]. (2013-08-21). http://news.xinhuanet.com/abroad/2013-08/21/c_125217105.htm.

[2] Hui Shao, Xiukun Ge, Haipu Bi, etc. Reflection on guidance and reform of engineering education accreditation to the specialty construction, Journal of Changzhou University (social science edition), 2014, 15(1):104-107,121.

[3] Dateng Zheng, Xubo Kuang, Taiping Zhou, etc. Discussion on the reform of numerical control technology course under the standard of Engineering Education accreditation, China Computer \& Communication, 2014, 12: 254-255.

[4] Zhong Chen, Rui Ma, Ci Tang, etc. MATLAB micro course teaching method under the standard of Engineering Education accreditation, China Education Info, 2014, 24:18-21.

[5] Dan Lv. Analysis of the development trend of Engineering Education in China, Vocational Technology, 2013, 10: 87-87. 